\title{
ASSESSING THE READABILTIY OF FREEWARE END-USER LICENSING AGREEMENTS
}

\author{
Janet J. Prichard, Bryant University, prichard@bryant.edu \\ Michael B. Hayden, Rhode Island College, mhayden@ric.edu
}

\begin{abstract}
The Internet provides users with numerous web sites for downloading free software. Popular sites often warrant the software to be virus and spyware fee. However, a number of these applications collect and transmit data back to the developers. End users typically consent to this data collection when they accept the terms presented in an End User License Agreement (EULA). This is often done without reading the agreements, perhaps because of the agreements' length and complexity. In this study, the authors examine the length, voice (passive or active), and reading complexity metrics for the EULAs of 100 popular freeware applications, in an attempt to determine whether they are written at a level recommended by readability experts.
\end{abstract}

Keywords: End-User License Agreements, EULAs, Readability, Freeware, Readability Formulas

\section{INTRODUCTION}

The Internet provides users with numerous web sites for downloading free software. One of the oldest and largest software repositories, Download.com, reportedly contains over 100,000 freeware, shareware, and demo titles. Another popular site, TuCows.com, contains over 45,000 titles. The number of downloads from these sites is truly staggering. The ten most popular Window's freeware programs on Download.com have been collectively downloaded 1.4 billion times. Such sites often state that the software is virus free and does not collect information without the knowledge or consent a user (i.e., it is spyware free). However, some of these applications are known to exchange extensive data with remote locations over the Internet. For example, Kazaa Pal's ${ }^{\circledR}$ End User License Agreement (EULA) states that:

"BetterInternet collects certain types of nonpersonally identifiable information about individuals who install the Software. This information may include your Internet protocol (IP) address, your domain, your operating system, your browser version, type and language and your Internet Service
Provider. BetterInternet also collects and may use certain other types of nonpersonally identifiable information, including: certain of the web pages that you view, the amount of time that you spend on certain websites, your responses to ads served by BetterInternet, certain software installed to your computer and software characteristics and preferences, nonpersonally identifiable information on web pages and forms, software usage characteristics and preferences, and your ZIP code. ... BetterInternet may share nonpersonally identifiable aggregate information about you with third parties, including advertisers."

Another agreement, for ICQ Pro, contains 40 references to tracking or monitoring, 30 references to advertising, 19 references to online promotions, and one reference to pop-up advertisements.

Many users are probably not aware that such privacyinvasive software components may be installed on their machines during the installation of the downloaded free software. But the user typically agrees to accept the installation of such components when accepting the End User License Agreement for the software. Acceptance of the license agreement is completed by clicking on an "I Agree" or "I Accept" button, or an equivalent, before completing the software installation. Disclosure clauses, often listing anything that a developer wants, are often buried deep within a license agreement.

Such clickwrap license agreements have generally been held as legally enforceable [18]. Based on current law, clickwrap agreements or EULAs are binding if the user:

- is forced to view the agreement,

- has to take some affirmative action to agree and is truthful in the information disclosed,

- is prevented from proceeding if he/she does not agree, and

- has the option to end use of the product and receive a refund.

Recently, several recent court decisions have refused to enforce specific terms contained in clickwrap 
agreements. However, these cases "suggest that courts are willing to accept the validity of clickwrap agreements in general, but have invalidated specific clauses based on "traditional contract doctrines such as unconscionability and public policy.” [1].

Clickware license agreements therefore generally represent legally binding contracts, yet it is widely recognized that many people do not read such agreements. One company, PC PitStop, included a clause in one of its EULAs that promised "a special consideration that may include money" to users who sent an email to the address listed in the EULA. It took four months, and more than 3,000 downloads, before one person finally wrote in and was awarded $\$ 1,000$ [15]. It may be that end users do not read license agreements because many such agreements are long, complex, and written in legal language. Literary experts estimate the average reading ability in the United States to be at the $7^{\text {th }}$ grade level [14], and readers at this level generally comprehend less than half of what they read. Experts therefore recommend that documents aimed for a large public audience should be written at no higher than a $5^{\text {th }}$ grade level.

While a number of studies have examined the readability of insurance, financial, and privacy documents, little has been done to examine the readability of EULAs. In this paper, the authors examine the readability of 100 of the most popular freeware applications available on Download.com. This was done in an attempt to determine whether such agreements come close to meeting readability goals suitable for documents distributed to the general population.

\section{READABILITY FORMULAS}

The term readability is used to describe the ease with which a document can be read and understood. Readability is often evaluated using mathematical formulas that measure intrinsic properties of the text, and the resulting metrics used to evaluate the suitability of the text for a particular audience. Readability formulas base their metrics on measures such as word counts, syllable counts, vocabulary lists, and the number of complex words present ignoring visual design and presentation. Hundreds of readability formulas have been developed [13], and a number have achieved widespread use.

Readability formulas only measure the structural difficulty of the material and therefore do have limitations [17]. These formulas ignore the semantics of the material, and do not consider the cohesion or coherence of the text. These formulas also do not account for other factors that influence reading comprehension, such as characteristics of the reader, comprehension activities and sociocultural context [20]. However, readability formulas are easy to automate and generate reproducible metrics, and the validity of readability formulas has been tested. Because of this, many government agencies now require that documents, such as loan agreements, rental agreements, and property purchase contracts, meet specific readability levels. Over 30 states have some form of plain language, or readability component in their insurance laws [21], and a number of states specify that insurance policies must be written at a minimum Flesch Reading Ease score to be judged "sufficiently readable" [21]. The validity of readability formulas has been tested in a number of court cases [10], and validated in a study of consumer health care information [8].

The following sections briefly discuss the readability formulas used in this study. It is worth noting that most readability formulas produce an estimate of the grade level of schooling required to "understand" the material. This estimated grade level is based upon a specified percentage of comprehension by a typical reader at that grade level, i.e., the percentage of correct answers on a test covering the material. Readability formulas generally target 50\% comprehension. Because of this, a reading metric estimating an $8^{\text {th }}$ grade level predicts that an average $8^{\text {th }}$ grade student would be at the limit of his/her reading comprehension with the material in question.

\section{Flesch Reading Ease Score}

The Flesch Reading Ease Score [6, 7] developed in 1948, is one of the most widely used readability formulas in use today. It is a standard used by many government agencies and is the U.S. Department of Defense standard [22]. Many states use this test to assess the readability of contracts and insurance policies [21]. This formula is considered suitable for all kinds of text. A Flesch Reading Ease score is calculated by using the average the number of syllables per word and average sentence length.

$$
\begin{aligned}
& \text { Flesch Reading Ease Score } \\
& \text { = 206.835-84.6 x ASW-1.015 x ASL } \\
& A S W=\text { average number of syllables per word } \\
& A S L=\text { average sentence length }
\end{aligned}
$$

The result is returned as a difficulty score ranging from 0 to 100. The higher the score, the easier the document is to read. The Flesch Reading Ease Score is often mapped to a grade level based upon a $50 \%$ comprehension rate (see Table 1). 
Table 1. Flesch Reading Ease Score Grade Map

\begin{tabular}{ccc}
\hline Flesch Score & Readability & Grade Level \\
\hline \hline $90-100$ & Very Easy & $5^{\text {th }}$ \\
$80-90$ & Easy & $6^{\text {th }}$ \\
$70-80$ & Fairly easy & $7^{\text {th }}$ \\
$60-70$ & Standard & $8^{\text {th }}$ or $9^{\text {th }}$ \\
$50-60$ & Fairly Difficult & $10^{\text {th }}$ to $12^{\text {th }}$ \\
$30-50$ & Difficult & $13^{\text {th }}$ to $16^{\text {th }}$ \\
$0-30$ & Very Difficult & College Grad \\
\hline
\end{tabular}

Flesch-Kincaid Grade Level Formula

The Flesch-Kincaid Grade Level formula, developed for the U. S. Navy in 1974 [12], is a modification of the Flesch Reading Ease formula. The FleschKincaid formula is a U.S. Department of Defense [22] standard and it has been used by the U.S. Navy for over 25 years. This formula is also widely used elsewhere and is considered to be well suited for business publications and journals.

$$
\begin{aligned}
& \text { Flesch Kincaid Grade Level } \\
& \quad=(0.39 \times \text { ASL })+(11.8 \times \text { ASW })-15.59 \\
& \text { ASL }=\text { average sentence length } \\
& \text { ASW }=\text { average number of syllables per word }
\end{aligned}
$$

\section{The Gunning Fog Formula}

The Gunning Fog Index [9], developed in 1952, estimates the number of years of education that a reader needs to understand the material. This formula calculates a grade level based on the average sentence length and the number of complex words, where "complex" is defined as words containing three or more syllables. The Gunning Fog Index targets 90\% comprehension. Gunning-Fog is widely used for evaluating business publications and journals.

$$
\begin{aligned}
& \text { Gunning Fog Index } \\
& \quad=0.4 \times(A S L+100 \times \text { Complex }) \\
& \text { ASL }=\text { average sentence length } \\
& \text { Complex }=\% \text { of words with } 3 \text { or more syllables }
\end{aligned}
$$

\section{SMOG Readability Formula}

The SMOG (Simple Measure of Gobbledygook) Readability formula [16], developed in 1969, assesses the educational level needed to understand material at a $100 \%$ comprehension level. The formula is calculated based on sentence length and number of complex words, where "complex" is defined as words containing three or more syllables. Because of the $100 \%$ comprehension level, the SMOG has been widely used in the health care industry and is generally considered appropriate for general text written at a $4^{\text {th }}$ grade through college level.

$$
\begin{aligned}
& \text { SMOG Grade Level } \\
& =1.0430 \mathrm{x} \\
& \text { sqrt(number of words with } \geq 3 \text { syllables } \\
& \quad \text { / number of sentences })+3.1291
\end{aligned}
$$

\section{Coleman Liau Formula}

The Coleman-Liau [2] readability formula calculates grade level based on average sentence lengths and average number of characters per word. This formula is considered appropriate for text written for $4^{\text {th }}$ grade to college level readers. This formula bases its calculation simply on characters and sentence length and does not use syllable counts, making the formula easier to automate.

$$
\begin{aligned}
& \text { Coleman Liau Formula } \\
& \quad=(5.89 \times \text { ACW })-0.3 \times(1 / A S L)-15.8 \\
& A C W=\text { average number characters per word } \\
& A S L=\text { average sentence length }
\end{aligned}
$$

\section{Automated Readability Index Formula}

The Automated Readability Index (ARI) formula [19], was developed in 1967 to assess U.S. Air Force materials. Like the Coleman Liau formula, this test calculates the U.S. grade level of a text sample based on average sentence length and average number of characters per word, and hence is easier to automate. The Automated Readability Index formula is considered most suitable for technical documents and manuals.

$$
\begin{aligned}
& \text { ARI Grade Level } \\
& \quad=(4.71 \times A C W)+(0.5 \times A S L)-21.43 \\
& A C W=\text { average number characters per word } \\
& A S L=\text { average sentence length }
\end{aligned}
$$

\section{Dale-Chall Readability Formula}

The Dale-Chall Readability formula, developed in 1948 [3] and revised in 1995 [4], is a vocabulary based test considered appropriate for any kind of text from the $4^{\text {th }}$ grade through college level. Readability is based upon average sentence length and the number of unfamiliar words (using a list of 3,000 common words).

$$
\begin{array}{r}
\text { Dale Chall Raw Score } \\
=(0.1579 \times \text { Dale Score })+ \\
(0.0496 \times \text { ASL })+3.6365
\end{array}
$$

Dale Score $=\%$ words not on common word list $A S L=$ average sentence length 
This formula yields a Raw Score that can be converted to a Grade Level based on a $50 \%$ comprehension rate (see Table 2).

Table 2. Dale-Chall Grade Levels

\begin{tabular}{cc}
\hline Raw Score & Grade Level \\
\hline \hline $0-4.9$ & $4^{\text {th }}$ and below \\
$5.0-5.9$ & $5^{\text {th }}$ or $6^{\text {th }}$ \\
$6.0-6.9$ & $7^{\text {th }}$ or $8^{\text {th }}$ \\
$7.0-7.9$ & $9^{\text {th }}$ or $10^{\text {th }}$ \\
$8.0-8.9$ & $11^{\text {th }}$ or $12^{\text {th }}$ \\
$9.0-9.9$ & $13^{\text {th }}$ to $15^{\text {th }}$ \\
10 and above & College Graduate \\
\hline
\end{tabular}

\section{RESEARCH METHODOLOGY}

One hundred and twenty-five of the most frequently downloaded Windows freeware programs, as of January 28, 2008, were downloaded from Download.com. These applications were installed on test machines and the licensing agreements captured and saved as text files. Several downloads were skipped because they were updates to other programs, or required Windows 95 or 98 . One application, Livewire, contained no license agreement. To obtain the desired 100 agreements, it was necessary to reach down to the $109^{\text {th }}$ item on the list of most popular downloads on Download.com.

During the installation process, all licensing information presented to the user was saved as text files. If an installation conspicuously displayed a hyperlink, directing a user to a site for additional terms, the hyperlink was followed. If the linked information referenced license terms, privacy policies, or security policies it was also captured and saved into the text file for the agreement. The links that referenced additional license terms, privacy, or security were followed to a maximum depth of one level. After completing the software installation, each application was run and any additional terms that were presented were also captured and saved to the text file for the agreement. For applications that required registration, the process was followed up to the point where personally identifiable information was requested for registration.

The text for each agreement was then examined. The agreement may have been edited for any of the following three reasons. First, if the agreement contained large blocks of foreign language text, then that foreign language text was removed. An occasional foreign phrase was left intact in the agreement. Second, lines of characters, such as dashes used as sectional or spatial separators, were removed. Third, some agreements were designed for display in small windows and utilized line-feed/ carriage-returns at the end of each line to control text wrapping. These were removed after initial testing showed that some readability tools interpreted these as end of sentence markers, greatly affecting their results.

Six software tools were used to then analyze the license agreements. These tools are free or inexpensive, and are readily found on the internet. They report a variety of readability results using the seven readability formulas discussed in the previous section. Also, though multiple tools may use the same readability formula, the results reported by each tool are often slightly different. The software tools used in this study include:

- Flesch 2.0 (http://flesch.sourceforge.net)

- Microsoft ${ }^{\circledR}$ Office Word 2007

- Readability Calculations V. 5.0 (Micro Light and Power Company)

- Readability Tools V.1.0 (Silicon Prairie Software)

- ReadMe V. 2.0 (Northern Arizona University)

- TxReadability (The Accessibility Institute, University of Austin)

\section{RESULTS}

Each of the six tools used in this study report the number of words or length of a document. But due to the different techniques employed by the tools to decide what constitutes a word, the tools rarely return exactly the same number of words for a given agreement. For example, one tool reported 29,500 words in an agreement, while another tool reported only 24,902 for the same agreement, a difference of 4,598. To simplify the discussion here, Table 3 uses the word counts as reported by Microsoft Word 2007.

Table 3. Agreement Lengths

\begin{tabular}{ccc}
\hline $\begin{array}{c}\text { Length } \\
\text { (Total Words) }\end{array}$ & $\begin{array}{c}\text { Number of } \\
\text { Agreements }\end{array}$ & $\begin{array}{c}\sim \text { Number of } \\
\text { Pages }\end{array}$ \\
\hline \hline $0-2,500$ & 46 & $<10$ \\
$2,501-5,000$ & 15 & $10-20$ \\
$5,001-7500$ & 12 & $20-30$ \\
$7,501-10,000$ & 3 & $30-40$ \\
$10,001-12,500$ & 7 & $40-50$ \\
$12,501-15000$ & 4 & $50-60$ \\
$15,001-16,500$ & 2 & $60-70$ \\
$17,501-20,000$ & 1 & $70-80$ \\
$20,001+$ & 10 & $80+$ \\
\hline \hline Range & 31 to 40,122 & \\
Mean & $6,656.05$ & \\
Std. Deviation & $8,728.40$ & \\
\hline
\end{tabular}


The mean agreement size was found to be 6,656 words, while approximately $27 \%$ of the agreements studied were longer than 10,000 words. There was considerable variation in the lengths of the agreements. The shortest agreement, for Atomic Clock Synch 2.7.0.3, was a brief 31 words long. However, the longest agreement, for ICQ Pro 2003b, was almost 1,300 times longer at 40,122 words. An 8.5 inch by 11 inch page, double spaced with one inch margins and using a 12 point font, contains an average of 250 words. Thus, the mean agreement length of 6,656 words represents an average of approximately 26.6 pages of text. The longest agreement, ICQ Pro 2003b, is approximately 160 double spaced pages of text. By comparison, the Federal 2005 IRS-1040 Instruction Booklet contained just 142 pages [11]. Also note that ICQ Pro 2003b requires that "You represent and warrant that you are at least 13 years old." and "You represent and warrant that you have the adequate legal capacity to enter into this Agreement.” The question that must be raised is whether a 13 year old has the ability to fully understand a 40,000+ word document that supposedly represents a binding legal contract, regardless of the complexity of the text contained therein.

\section{Voice}

Plain English guidelines generally recommended the use of active voice [5]. For example, the U.S. Security and Exchange Commission's widely used "A Plain English Handbook: How to create clear SEC disclosure documents" [23] recommends that one "Use the passive voice only when you have a very good reason for doing so.” because "Many times the passive voice forces readers to take extra mental steps as they convert the passive into the active."
Microsoft Word 2007 reports the percentage of a document written in the passive voice, and was used for this part of the study. Of all the agreements analyzed, six managed to avoid using the passive voice completely. As shown in Table 4, the majority of the agreements had $10-30 \%$ of their text written in the passive voice. The highest percentage of passive sentences was 42\% (No-IP 2.2.1). Approximately $40 \%$ of the agreements used the passive voice more than $20 \%$ of the time.

Table 4. Number of Agreements and Percentage of Passive Sentences

\begin{tabular}{cc}
\hline Passive Sentences & Number of Agreements \\
\hline \hline $0 \%$ & 6 \\
$0-10 \%$ & 6 \\
$10-20 \%$ & 48 \\
$20-30 \%$ & 31 \\
$30-40 \%$ & 8 \\
$>40 \%$ & 1 \\
\hline \hline Range & 0 to $42 \%$ \\
Mean & $19 \%$ \\
Std. Deviation & $8 \%$ \\
\hline
\end{tabular}

\section{Readability}

Table 5 contains a summary of the Flesch Reading Ease Scores for the agreements tested. All six of the tools used in this study report Flesch Reading Ease Scores. Readability formulas generally require a minimum 100 word sample size to produce reliable results, so agreements that were reported with less than 100 words by any of the tools were not tested, leaving a sample size of 94 agreements. As mentioned earlier, the tools not only produce different word counts for the same agreement, but also show a variation in the reported values for a

Table 5. Flesch Readability Scores

\begin{tabular}{|c|c|c|c|c|c|c|c|}
\hline $\begin{array}{c}\text { Flesch } \\
\text { Reading } \\
\text { Ease Score }\end{array}$ & Difficulty & $\begin{array}{c}\text { MS Word } \\
2007 \\
\end{array}$ & Flesch 2.0 & $\begin{array}{c}\text { ReadMe } \\
2.0 \\
\end{array}$ & $\begin{array}{c}\text { Read } \\
\text { Calc } 5.0\end{array}$ & TxRead & $\begin{array}{c}\text { Read } \\
\text { Tools } 1.0\end{array}$ \\
\hline $90-100$ & Very Easy & $0.0 \%$ & $0.0 \%$ & $0.0 \%$ & $0.0 \%$ & $0.0 \%$ & $0.0 \%$ \\
\hline $80-90$ & Easy & $0.0 \%$ & $0.0 \%$ & $0.0 \%$ & $0.0 \%$ & $0.0 \%$ & $0.0 \%$ \\
\hline $70-80$ & Fairly Easy & $0.0 \%$ & $0.0 \%$ & $0.0 \%$ & $2.1 \%$ & $0.0 \%$ & $0.0 \%$ \\
\hline $60-70$ & Standard & $1.1 \%$ & $2.1 \%$ & $2.1 \%$ & $10.6 \%$ & $3.2 \%$ & $3.2 \%$ \\
\hline $50-60$ & Fairly Difficult & $3.2 \%$ & $1.1 \%$ & $2.1 \%$ & $26.6 \%$ & $4.3 \%$ & $2.1 \%$ \\
\hline $30-50$ & Difficult & $73.4 \%$ & $80.9 \%$ & $60.6 \%$ & $59.6 \%$ & $68.1 \%$ & $88.3 \%$ \\
\hline $0-30$ & Very Difficult & $22.3 \%$ & $16.0 \%$ & $35.1 \%$ & $1.1 \%$ & $24.5 \%$ & $6.4 \%$ \\
\hline Score Range & & 9.6 to 68.3 & 13.0 to 66.7 & 7.6 to 66.1 & 26.0 to 76.0 & 5.6 to 68.3 & 18.2 to 66.9 \\
\hline Mean & & 34.8 & 36.6 & 32.9 & 49.9 & 35.3 & 40.5 \\
\hline Std. Dev. & & 8.5 & 8.5 & 9.0 & 8.4 & 9.4 & 7.7 \\
\hline
\end{tabular}


given readability formula. This variability is most likely due to differences in calculating average sentence lengths and average syllables per word.

A Flesch Reading Ease Score of 60 or more, considered to be Plain English, is a desirable target for material read by the general populace. Five of the six readability tools produced metrics indicating that there were single digit percentages of agreements written in what would be considered Plain English. One of the tools, Readability Calculations 5.0, consistently gave higher scores than the other five tools, and indicated that $12.7 \%$ of the agreements would be considered Plain English. Four of the six tools produced mean readability scores in the low-tomid 30s, which is noteworthy because these scores are quite close to the 32 Flesch Reading Ease Score for the Harvard Law Review [14].

As mentioned earlier, a number of states specify a minimum Flesch Reading Ease Score that insurance policies must meet to be considered "sufficiently readable”. The score needed generally ranges between 40 (e.g., Hawaii, Tennessee, Ohio) and 50 (e.g., Maine, Massachusetts, North Carolina, Texas). Using a Flesch Reading Ease Score of 40 (Difficult), four of the six tools showed results of less than $30 \%$ of the agreements in this study met this goal. Using a Flesch Reading Ease Score of 50, five of the six tools showed that only $3.2 \%-7.5 \%$ of the agreements in this study met this goal. Using all six tools, anywhere from $60.7 \%$ - $96.9 \%$ of the agreements studied were categorized as either difficult or very difficult.

Table 6 summarizes the Flesch-Kincaid Grade Level results. Two of the tools used (Readability Calculations 5.0 and Readability Tools) returned mean readability grade levels of approximately 12, which reflect a high school graduate reading level. The other four programs returned means indicating that the agreements were written at a $14^{\text {th }}$ grade level $\left(2^{\text {nd }}\right.$ year college $)$. Since the average reading ability in the United States is estimated to be at a $7^{\text {th }}$ grade [14], these results would indicate only between 3.2\% and $9.6 \%$ of these agreements would be easily read and comprehended by the general population. Readability experts recommend that documents aimed for a large public audience should be written at no higher than a $5^{\text {th }}$ grade level. None of the agreements tested met this requirement.

Two tools tested both the FOG and SMOG readability formulas and their results are shown in Table 7 . The results obtained are higher than those

Table 6. Flesch-Kincaid Grade Level

\begin{tabular}{ccccccc}
\hline $\begin{array}{c}\text { Grade } \\
\text { Level }\end{array}$ & $\begin{array}{c}\text { MS Word } \\
\mathbf{2 0 0 7}\end{array}$ & Flesch 2.0 & $\begin{array}{c}\text { ReadMe } \\
\mathbf{2 . 0}\end{array}$ & $\begin{array}{c}\text { Read } \\
\text { Calc 5.0 }\end{array}$ & TxRead & $\begin{array}{c}\text { Read } \\
\text { Tools 1.0 }\end{array}$ \\
\hline \hline $0-5$ & $0.0 \%$ & $0.0 \%$ & $0.0 \%$ & $0.0 \%$ & $0.0 \%$ & $0.0 \%$ \\
$6-8$ & $3.2 \%$ & $3.2 \%$ & $3.2 \%$ & $9.6 \%$ & $6.4 \%$ & $4.3 \%$ \\
$9-12$ & $17.0 \%$ & $27.7 \%$ & $16.0 \%$ & $58.5 \%$ & $14.9 \%$ & $57.4 \%$ \\
$13-16$ & $71.3 \%$ & $60.6 \%$ & $62.8 \%$ & $31.9 \%$ & $66.0 \%$ & $36.2 \%$ \\
$17+$ & $8.5 \%$ & $8.5 \%$ & $18.1 \%$ & $0.0 \%$ & $12.8 \%$ & $2.1 \%$ \\
\hline \hline Range & 7.2 to 19.4 & 7.7 to 20.2 & 7.7 to 21.9 & 6.3 to 15.7 & 6.5 to 22.4 & 6.8 to 18.1 \\
Mean & 14.2 & 14.0 & 14.9 & 11.9 & 14.3 & 12.4 \\
Std. Dev. & 2.2 & 2.2 & 2.4 & 2.0 & 2.8 & 1.9 \\
\hline
\end{tabular}

Table 7. FOG and SMOG Grade Levels

\begin{tabular}{|c|c|c|c|c|}
\hline \multirow[b]{2}{*}{$\begin{array}{l}\text { Grade } \\
\text { Level } \\
\end{array}$} & \multicolumn{2}{|c|}{ Gunning Fog Grade Level } & \multicolumn{2}{|c|}{ SMOG Grade Level } \\
\hline & $\begin{array}{c}\text { Read } \\
\text { Tools } 1.0\end{array}$ & $\begin{array}{c}\text { Read } \\
\text { Calc } 5.0\end{array}$ & $\begin{array}{c}\text { Read } \\
\text { Tools } 1.0\end{array}$ & $\begin{array}{c}\text { Read } \\
\text { Calc } 5.0\end{array}$ \\
\hline $0-5$ & $0.0 \%$ & $0.0 \%$ & $0.0 \%$ & $0.0 \%$ \\
\hline $6-8$ & $0.0 \%$ & $0.0 \%$ & $0.0 \%$ & $0.0 \%$ \\
\hline $9-12$ & $7.4 \%$ & $0.0 \%$ & $13.8 \%$ & $34.0 \%$ \\
\hline $13-16$ & $64.9 \%$ & $4.3 \%$ & $79.8 \%$ & $66.0 \%$ \\
\hline $17+$ & $27.7 \%$ & $95.7 \%$ & $6.4 \%$ & $0.0 \%$ \\
\hline Range & 9.4 to 23.8 & 14.0 to 31.6 & 9.8 to 20.1 & 9.3 to 16.4 \\
\hline Mean & 16.1 & 23.2 & 14.5 & 13.2 \\
\hline Std. Dev. & 2.3 & 2.8 & 1.7 & 1.3 \\
\hline
\end{tabular}


Table 8. Coleman-Liau and ARI Levels

\begin{tabular}{ccccc}
\hline & Coleman Liau & & \multicolumn{2}{c}{ ARI } \\
\cline { 2 - 3 } \cline { 5 - 5 } Grade & Read & ReadMe & Read \\
Level & Calc 5.0 & & $\mathbf{2 . 0}$ & Tools 1.0 \\
\hline \hline $0-5$ & $0.0 \%$ & & $0.0 \%$ & $1.1 \%$ \\
$6-8$ & $0.0 \%$ & $3.2 \%$ & $3.2 \%$ \\
$9-12$ & $7.4 \%$ & & $16.0 \%$ & $55.3 \%$ \\
$13-16$ & $91.5 \%$ & & $58.5 \%$ & $38.3 \%$ \\
$17+$ & $1.1 \%$ & & $22.3 \%$ & $2.1 \%$ \\
\hline \hline Range & 10.7 to 18.0 & & 6.7 to 22.9 & 5.4 to 18.8 \\
Mean & 14.2 & & 15.1 & 12.3 \\
Std. Deviation & 1.1 & & 2.9 & 2.2 \\
\hline
\end{tabular}

for the Flesch Grade Level, but this is to be expected as both tests assume a much higher percentage of comprehension that do the Flesch formulas. Both programs calculated FOG Grade Levels of college graduate or higher, and both tools calculated that the majority of agreements had SMOG Grade Levels in the college level range $\left(13^{\text {th }}\right.$ to $16^{\text {th }}$ grade).

Results for the Coleman-Liau and ARI readability formulas are shown in Table 8. The Coleman-Liau mean grade level is approximately Grade 14, or two years of college. Two of the tools provided ARI evaluations. The first indicated a mean $15^{\text {th }}$ Grade $\left(3^{\text {rd }}\right.$ year college) reading level while the second test resulted in a $12^{\text {th }}$ Grade, or high school reading level.

The Dale Chall formula returned a mean raw score of 8.9 which converts to an average $11^{\text {th }}$ or $12^{\text {th }}$ grade reading level (see Table 9). Since the Dale-Chall formula assumes $50 \%$ comprehension, the average agreement would not be fully understood by typical high school juniors or seniors.

Table 9. Dale-Chall Levels

\begin{tabular}{ccc}
\hline $\begin{array}{c}\text { Dale Chall } \\
\text { Raw Score }\end{array}$ & $\begin{array}{c}\text { Read } \\
\text { Calc 5.0 }\end{array}$ & Grade Level \\
\hline \hline $0-4.9$ & $0.0 \%$ & $4^{\text {th }}$ and below \\
$5.0-5.9$ & $0.0 \%$ & $5^{\text {th }}$ or $6^{\text {th }}$ \\
$6.0-6.9$ & $1.1 \%$ & $7^{\text {th }}$ or $8^{\text {th }}$ \\
$7.0-7.9$ & $8.5 \%$ & $9^{\text {th }}$ or $10^{\text {th }}$ \\
$8.0-8.9$ & $40.4 \%$ & $11^{\text {th }}$ or $12^{\text {th }}$ \\
$9.0-9.9$ & $45.7 \%$ & $13^{\text {th }}$ to $15^{\text {th }}$ \\
10 and above & $4.3 \%$ & College \\
\hline Range & 6.4 to 10.6 & Graduate \\
Mean & 8.9 & \\
Std. Deviation & 0.7 & \\
\hline
\end{tabular}

\section{CONCLUSIONS}

Clearly this study has shown that the majority of popular free software license agreements are lengthy and difficult to read. Hence, it is not surprising that people rarely take the time to read these agreements, or indeed have the ability to comprehend the agreements if they do read them. Yet users are willing to say that they agree to the terms contained within the agreements so as to be able to load the associated software. This allows companies and developers opportunity to disclose and sanction information gathering activities that the user is most likely unaware of. If consumers were aware that this is part of the "cost" of using the software, they might decide that compromising their privacy carries too high of a cost. Companies and developers have an ethical obligation to improve the readability of these agreements to make it easier for consumers to make informed choices about the real cost of installing and using the "free" software.

Another troubling aspect of the difficulty in reading these agreements is that the software often targets younger people. As mentioned earlier, some of the agreements require that the user be at least 13 years of age, which is the typical age of a $7^{\text {th }}$ grader. Most of these tools and readability formulas have indicated that very few of the agreements would be readable by a $7^{\text {th }}$ grader, yet much of the software used by this age group is represented in the 100 top downloads used in this study. It is also interesting to note that one product, Roger Wilco, presented a EULA after the user entered demographic information including their name and birth date. When a birth date for a five year old was entered, the software still allowed the user to accept the terms of agreement that started with the sentence "You must be at least 13 to accept these Agreements", and continue installation of the product. 
In conducting this study, it became evident that tools that are readily available for testing readability have varying results for the same agreement text. This variation was evident in simple results such as word counts, to more complex tasks such as computing word syllabus counts. Future research will explore evaluating the accuracy of these tools.

\section{REFERENCES}

1. Anderson, R. C. (2007). Enforcement of contractual terms in clickwrap agreements. Shidler Journal of Law, Commerce \& Technology, 3(11). Retrieved December 22, 2007, from

http://www.lctjournal.washington.edu/Vol3/a011 Cormier.html.

2. Coleman, M., \& Liau, T. L. (1975). A computer readability formula designed for machine scoring. Journal of Applied Psychology, 60(2), 283-284.

3. Dale, E., \& Chall, J. S. (1948). A formula for predicting readability. Educational Research Bulletin, 27, 37-54.

4. Dale, E., \& Chall, J. S (1995). Readability revisited: The new Dale-Chall readability formula. Cambridge, MA: Brookline Books.

5. The Plain Language Action and Information Network. Federal plain language guidelines. Retrieved March 2, 2008 from http://www.plainlanguage.gov/howto/ guidelines/bigdoc/fullbigdoc.pdf.

6. Flesch, R. (1948). A new readability yardstick. Journal of Applied Psychology, 32, 221-233.

7. Flesch, R. (1979). How to write plain English. New York, NY: Harper and Row.

8. Gemoets, D., Rosemblat, G., Tse, T., \& Logan, R. (2004). Assessing readability of consumer health information: An exploratory study. In Fieschi, M. \& Coiera, E. (Eds.) Medinfo 2004: Proceedings of the 11th World Congress on Medical Informatics. 2004; San Francisco, CA. Amsterdam: IOS Press, 869-878.

9. Gunning, R. (1952). The technique of clear writing. New York, NY: McGraw-Hill International.

10. Imber, S. C. (2001). The Miranda Warning: Readability and the rights of children with disabilities. Forensic Psychology Monographs, 1.

11. Keating, D. (2005). A taxing trend: The rise in complexity, forms, and paperwork burdens. National Taxpayers Union Policy Paper 120. Retrieved December 21, 2007 from http://www.ntu.org/main/press_papers.php?Press ID=829\&org_name=NTU.
12. Kincaid, J. P., Fishburne, R. P, Rogers, R. L. \& Chissom, B. S. (1975). Derivation of new readability formulas (Automated Readability Index, Fog Count and Flesch Reading Ease Formula) for Navy enlisted personnel. Research Branch Report 8-75. Memphis, TN.: Naval Air Station.

13. Klare, G. (1974-1975). Assessing readability. Reading Research Quarterly, 10(1), 62-103.

14. Lutz, W. (2004). Affidavit on the readability of privacy notices. Retrieved January 21, 2008 from http://epic.org/privacy/glba/.

15. Magid, L. It pays to read license agreements. Retrieved February 2, 2008 from http://pcpitstop.com/spycheck/eula.asp.

16. McLaughlin, H. (1969). SMOG grading - a new readability formula. Journal of Reading, 22, 639646.

17. Redish, J. (2000). Readability formulas have even more limitations than Klare discusses. ACM Journal of Computer Documentation, 24(3), 132-137.

18. Scott, M. D. (2007). Scott on Information Technology Law (3 ${ }^{\text {rd. }}$ ed.). New York, NY: Aspen Publishers Online.

19. Smith, E. A. \& Senter, R. J. (1967). Automated Readability Index. AMRL-TR, 66-22. WrightPatterson AFB, OH: Aerospace Medical Division.

20. Rand Corporation. (2002). Reading for understanding: Toward an $R \& D$ program in reading comprehension. Santa Monica, CA: Author.

21. Stempel, J. W. (2005). Stempel on Insurance Contracts ( $3^{\text {rd. }}$ ed.). New York, NY: Aspen Publishers.

22. U.S. Department of Defense (1995). Standard practice for manuals, technical: General style and format requirements (MIL-STD-38784). Washington, DC: Government Printing Office.

23. U.S. Security and Exchange Commission (1998). A Plain English handbook: How to create clear SEC disclosure documents. Washington, DC: Office of Investor Education and Assistance U.S. Securities and Exchange Commission. 